\title{
The surgical personality: comparisons between urologists, non-urologists and non-surgeons
}

\author{
Andrew E. MacNeily, MD, FRCSC; ${ }^{*}$ Lynn Alden, PhD; ${ }^{\dagger}$ Eric Webber, MD, FRCSC;, Kourosh Afshar, MD, FRCSC ${ }^{* \xi}$ \\ *Department of Urologic Sciences, University of British Columbia, Vancouver, BC; 'Department of Psychology, University of British Columbia, Vancouver, BC; ${ }^{ \pm}$Department of Surgery,

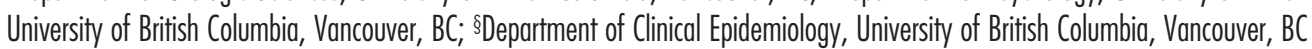

See related article on page 186 .

Cite as: Can Urol Assoc J 2011;5(3):182-5; D01:10.5489/cuaj.10142

\begin{abstract}
Background: Our objective was to compare personality traits between urologists and other surgeons, as well as between surgeons and non-surgeons.

Methods: Eighty-six surgeons (57 faculty, 29 residents) completed the Revised NEO Personality Inventory (NEO PI-R), a validated measure of normal personality traits. Subjects agree or disagree with 240 statements to generate a score in each of the 5 major character traits: extraversion $(E)$, openness $(O)$, conscientiousness $(C)$, agreeableness (A) and neuroticism (N). Each factor is subdivided into 6 component facets. Scores for urology faculty and residents were compared to the other surgical groups and 21 pediatricians. Results: The 3 groups differed significantly on extraversion $(p<0.001)$. Post-hoc analyses indicated that urologists obtained significantly higher extraversion scores than other surgeons $(p<0.05)$ and non-surgeons $(p<0.001)$ Other surgeons also scored significantly higher than non-surgeons on the extraversion factor $(p<0.05)$. No significant differences emerged on openness, conscientiousness, agreeableness or neuroticism. Of the 6 extraversion facets, urologists obtained significantly higher scores on gregariousness and excitement-seeking $(p<0.05)$ than non-urologist surgeons, and significantly higher scores on gregariousness $(p<0.05)$, activity $(p<0.01)$, excitement seeking $(p<0.001)$, and positive emotions $(p<0.05)$ than non-surgeons. Non-urologist surgeons obtained significantly higher scores than non-surgeons on Activity and Excitement-seeking $(p<0.01)$. There were no significant differences in the facets of warmth or assertiveness.

Interpretation: Urologists appear to be more extraverted compared to other surgeons. Both groups of surgeons were more extraverted than non-surgeons. If these findings can be confirmed on a wider basis, the data may be helpful in resident selection, mentoring, evaluation and career counselling.
\end{abstract}

\section{Résumé}

Contexte : Notre objectif était de comparer des urologues à d'autres chirurgiens, ainsi que des chirurgiens avec des médecins non chirurgiens, sur le plan de certains traits de personnalité.

Méthodologie : Quatre-vingt-six chirurgiens (57 membres du personnel universitaire, 29 résidents) ont rempli le questionnaire NEOPI-R (Revised NEO Personality Inventory), un instrument validé de mesure de traits normaux de la personnalité. Les sujets doivent indiquer leur accord ou désaccord avec 240 énoncés et obtiennent ainsi un score pour chacun des 5 principaux traits de personnalité : extraversion $(E)$, ouverture $(\mathrm{O})$, caractère consciencieux $(\mathrm{C})$, personnalité agréable $(\mathrm{A})$ et névrosisme $(\mathrm{N})$. Chaque facteur est sous-divisé en 6 facettes. Les scores pour les urologues et les résidents ont été comparés à ceux d'autres groupes de chirurgiens et à ceux de 21 pédiatres.

Résultats : Les 3 groupes différaient de façon significative sur le plan de l'extraversion $(p<0,001)$. Les analyses ultérieures ont indiqué que les urologues avaient obtenu des scores significativement plus élevés sur le plan de l'extraversion que les autres chirurgiens $(p<0,05)$ et les médecins non-chirurgiens $(p<0,001)$. Les autres chirurgiens ont aussi obtenu des scores significativement plus élevés que les non-chirurgiens pour l'extraversion $(p<0,05)$. Aucune différence significative n'est ressortie quant à l'ouverture, au caractère consciencieux, à la personnalité agréable ou au névrosisme. Sur les 6 facettes de l'extraversion, les urologues ont obtenu des scores significativement plus élevés pour l'instinct grégaire et la recherche de stimulation $(p<0,05)$ par rapport aux chirurgiens non-urologues, et des scores significativement plus élevés pour I'instinct grégaire $(p<0,05)$, le niveau d'activité $(p<0,01)$, la recherche de stimulation $(p<0,001)$, et les émotions positives $(p<0,05)$ par rapport aux médecins non-chirurgiens. Les chirurgiens non-urologues ont obtenu des scores significativement plus élevés que les médecins non-chirurgiens quant au niveau d'activité et à la recherche de stimulation $(p<0,01)$. On n'a noté aucune différence significative pour les facettes de la personnalité chaleureuse ou de l'affirmation de soi.

Interprétation : Il semble que les urologues soient plus extravertis que les autres chirurgiens. Les deux groupes de chirurgiens étaient plus extravertis que les non-chirurgiens. Si ces résultats sont confirmés dans un échantillon plus important, les données pourraient 
aider à la sélection des résidents, au mentorat, à l'évaluation et au counselling professionnel.

\section{Introduction}

It is often perceived that the presence of a distinct surgical personality plays an important role in the selection process of surgical residents and may help predict their success in a surgical residency and career. We previously reported data demonstrating that urology residents possessed distinct normal personality traits in comparison to the general population. ${ }^{1}$ The question remains whether this difference persists in comparison to other types of surgeons or other non-surgeons. The purpose of this study was to compare differences in normal personality traits between urologists and non-urologist surgeons, as well as between surgeons and non-surgeons.

\section{Methods and materials}

\section{Research instrument}

We employed the Revised NEO Personality Inventory (NEO $\mathrm{PI}-\mathrm{R}$ ) to measure the personality attributes of a sampling of faculty surgeons and non-surgeons at the University of British Columbia (UBC). The details of the NEO PI-R have been explained previously. ${ }^{2}$ In brief, it provides a concise measure of the major 5 factors of normal personality: extraversion $(\mathrm{E})$, openness $(\mathrm{O})$, conscientiousness $(\mathrm{C})$, agreeableness $(\mathrm{A})$ and neuroticism $(\mathrm{N})$. Each of these factors is further subdivided into 6 facets, for a total of 30 personality domains. This validated, self-reported inventory consists of 240 short statements answered using a 5-point rating scale. This tool was developed explicitly to assess normal personality and, accordingly, norms have been developed for the non-clinical population of North American men and women.

\section{Subjects}

We obtained approval for this study from the institutional behavioural research ethics board. In February 2007, personality inventories were mailed out to all 16 UBC faculty urologists, 81 faculty surgeons and 51 general pediatricians in the lower mainland of BC. Stamped, self-addressed return envelopes were provided. The participation of UBC urology residents was voluntarily accumulated over the course of academic years, from 2002 to 2007.

\section{Results}

Owing to the small number of female faculty, only an analysis of male responses was performed. Overall, 86 surgeons ( 9 faculty urologists, 29 urology residents and 48 non-urologist surgeons from the UBC divisions of general, plastic, vascular, orthopedic, cardiac, otolaryngology and neurosurgery) anonymously completed the NEO PI-R, for a response rate of $68 \%(86 / 126) ; 21 / 51$ pediatricians responded, for a response rate of $42 \%$. Scores for urology faculty and residents were combined and compared to the other surgical groups, and to the non-surgeons.

Participants' raw NEO scores were converted to percentile scores based upon norms in the test manual that are computed from a large, representative sample of the general population. A multivariate analysis of variance (MANOVA) on the $6 \mathrm{NEO}-\mathrm{PI}$ percentile scores revealed a significant group effect $(F[10,199]=3.50, p<0.001)$. Follow-up ANOVAs indicated that the between-group difference was due to a significant group effect on extraversion $(F[2,106]=7.69$, $p<0.001)$. To determine how the 3 groups compared to each other, post-hoc least significant differences (LSD) analyses were conducted. These analyses indicated that urologists scored significantly higher on extraversion than non-urologist surgeons $(p<0.05)$ and non-surgeons $(p<0.001)$. The mean percentile scores were $74 \%$ versus $61 \%$ and $43 \%$ for the non-urologist surgeons and non-surgeons, respectively (Table 1). The non-urologist surgeons also scored significantly higher $(p<0.05)$ than the non-surgeons.

To elucidate which particular facets of extraversion explained the higher scores for surgeons, one-way (group) ANOVAs were conducted on the 6 extraversion scores. These analyses revealed significant group effects on gregariousness $(F[2,106]=6.27, p<0.01)$, activity $(F[2,106]=4.63$, $p<0.05$, excitement-seeking $(\mathrm{F}[2,106]=12.95, p<0.001)$ and positive emotions $(F[2,106]=3.50, p<0.05)$. No significant differences emerged on warmth or assertiveness (Table 2). Post-hoc LSD analyses indicated that the urologists obtained significantly higher scores than non-urologist surgeons on gregariousness and excitement-seeking $(p<0.05)$. The urologists obtained significantly higher scores than the non-surgeons on gregariousness, activity, excitement-seeking and positive emotions $(p<0.01)$. The non-urologist surgeons obtained significantly higher scores than the non-surgeons

\begin{tabular}{|c|c|c|c|}
\hline Personality factor & Urologists & $\begin{array}{c}\text { Non-urologist } \\
\text { surgeons }\end{array}$ & Non-surgeons \\
\hline Extraversion* & $74^{a}$ & $61^{b}$ & $43^{c}$ \\
\hline Openness & 53 & 58 & 56 \\
\hline Conscientiousness & 62 & 71 & 63 \\
\hline Agreeableness & 50 & 54 & 61 \\
\hline Neuroticism & 47 & 41 & 44 \\
\hline
\end{tabular}




\begin{tabular}{|c|c|c|c|}
\hline $\begin{array}{l}6 \text { Extraversion } \\
\text { facet scales }\end{array}$ & Urologists & $\begin{array}{l}\text { Non-urologist } \\
\text { surgeons }\end{array}$ & Non-surgeons \\
\hline Gregariousness** & $69^{\mathrm{a}}$ & $53^{c}$ & $42^{c}$ \\
\hline Activity* & $76^{a}$ & $77^{\mathrm{a}}$ & $59^{c}$ \\
\hline $\begin{array}{l}\text { Excitement } \\
\text { seeking**** }\end{array}$ & $66^{a}$ & $52^{b}$ & $26^{c}$ \\
\hline Positive emotions* & $66^{\mathrm{a}}$ & $57^{\mathrm{ac}}$ & $43^{c}$ \\
\hline Warmth & 61 & 47 & 50 \\
\hline Assertiveness & 65 & 66 & 59 \\
\hline
\end{tabular}

Note: denotes significant between-group effect at $p<.05^{*}, p<.01^{* *}$, and $p<.001^{* * *}$. Groups with different superscripts differ significantly; superscripts containing same letters indicate non-significance.

on activity and excitement-seeking $(p<0.01)$. Controlling for age of respondents had no effect upon the results.

\section{Discussion}

The 5 NEO PI-R factors reflect the 5 major dimensions of personality. Compared to a peer group of surgeons, urologists scored significantly higher on extraversion than the other surgeons. Extraverts are typified by such characteristics as sociability, assertiveness and activity. They like excitement and stimulation, and tend to be upbeat, energetic and optimistic. Surgeons in general scored higher than non-surgeons in this factor as well.

The 4 facets of Extraversion distinguishing the surgical group from the non-surgical justify further explanation: gregariousness reflects the preference for other people's company. The mean score for urologists was higher than that of non-surgeons ( $69 \%$ vs. $42 \%$, respectively) on this dimension. Both groups of surgeons obtained significantly higher scores on activity relative to non-surgeons ( $76 \%$ and $77 \%$ vs. $59 \%$ ). High activity scores characterize people who have a rapid tempo, a sense of energy, a need to keep busy and who lead fast-paced lives. The 2 groups of surgeons also scored higher on excitement-seeking than non-surgeons $(66 \%$ and $52 \%$ vs. $26 \%$ ). Higher scores on this scale reflect enjoyment of excitement and stimulation. Finally, urologists were characterized by higher scores on the positive emotions facet of extraversion than non-surgeons ( $66 \%$ vs. $43 \%$ ) This facet assesses the tendency to experience positive emotions, such as joy, happiness, love and excitement. People with such scores are typically cheerful, optimistic and high-spirited. It is notable that high scores on positive emotions are associated with psychological adjustment and a sense of personal well-being.

It is worth noting that the non-surgeon group also obtained a higher mean score on the activity facet than the general population, which suggests that they too are energetic and like to keep busy. The non-surgeon group obtained a lower mean score on excitement-seeking relative to the general population. The latter scores indicate that, on average, nonsurgeons feel little need for thrills and prefer a more routine life than others.

The United States Air Force has employed standardized personality testing of its applicants since 1994 as part of their pilot selection process. ${ }^{2-4}$ Research into the personality profile of pilots has shown that testing for psychopathology is of limited benefit, while measures of normal personality characteristics, such as the NEO PI-R, have been useful in providing career counselling to student pilots. ${ }^{3}$ Similarly, the possible existence of a distinct "surgical personality" has lead to the consideration of using personality assessment in the selection and evaluation of surgical candidates and residents. It has been postulated that those who lack the requisite personality may be more prone to fail in completing residency, but this has not been demonstrated. Despite the lack of widespread use of validated personality measurement tools in surgical education, the assessment of personality traits appears to be an important component of resident evaluations. In a national survey of surgical program directors, $27 \%$ of the factors considered in resident evaluation were related to personality traits, despite the fact that such evaluations continue to be highly subjective. ${ }^{5}$ Before residency training programs can begin to adopt the use of standardized personality measurement tools, further characterization of the personalities of various specialty groups is necessary.

This study was performed as a follow up to our previously reported preliminary assessment of the normal personality characteristics of Canadian urology residents. In that study, we demonstrated that compared to a normative sample of North American adults, urology residents obtained significantly higher scores on extraversion, openness and conscientiousness. However, resident trainees are drawn from a highly select population: physicians. Therefore, our current aim was to further characterize the normal personality traits of urologists, surgeons and a group of non-surgeons. Pediatricians were chosen to represent the non-surgical arm of the study as they are, arguably, one of the least procedurally oriented of all specialties.

Our current results suggest that urologists in particular and surgeons in general, differ from non-surgeons only in the extraversion facet of normal personality characteristics. There were no significant differences between groups in terms of openness and conscientiousness. This result is not surprising given that individuals who score high on openness tend to be willing to entertain new ideas and unconventional values, the opposite of dogmatism. One would anticipate that most physicians would possess this trait. Higher than average scores on conscientiousness are generally found in people who are purposeful and determined; high scorers tend to be academic and occupational achievers, a trait perceived to be common to all physicians. 
Interestingly, our findings differ from those of Magee and colleagues. ${ }^{6}$ These authors applied the NEO PI-R ${ }^{\odot}$ to a 4-year cohort of graduating medical school students from Tulane University in an attempt to correlate student personality traits with ultimate residency matching results. Although there were some differences among matched specialties in neuroticism, openness and agreeableness, there were no differences for extraversion or conscientiousness. In particular, students matching to pediatrics scored significantly higher than those matching to surgery on neuroticism, openness and agreeableness with no differences on extraversion. It is possible that their findings differ from ours because the authors assessed the input to residency (undergraduate medical students), while we studied the final product. It has been suggested that personality differences between specialists might intensify after residency and certain characteristics may be more or less pronounced over time, as medical students adapt to different training and practice environments specific to their specialty. ${ }^{\text {? }}$

Several limitations of this study warrant mention. Our subjects are all drawn from a convenience sample at only one institution. Any commonality in personality characteristics of our study groups may be a reflection of an institutional preference for individuals with certain personality characteristics. (In fact, it may be at the expense of selecting introverted candidates.) This "like attracts like" model in which institutions tend to recruit trainees and faculty with similar personality traits limits the acceptance and implementation of our findings without further multi-institutional assessments. In addition, it could be argued that the inclusion of residents (who are younger than faculty) in the urological arm of the study could have altered overall scores for urologists and surgeons. However, controlling for age had no effect on these results, and others have shown that results on the NEO PI-R are stable throughout adulthood. ${ }^{8}$ Although we have demonstrated some unique personality characteristics of urologists and surgeons, it would be premature to conclude from our findings that career satisfaction or success in surgery and/or urology depends on a particular personality profile. Finally, because there were so few female faculty members in the surgical arms of the study, we were unable to assess the influence of gender in the 3 groups. However, in general, the effect of gender upon the personality profiles of physician role models and medical students has previously been described as only modest. ${ }^{9,10}$

It remains debatable whether psychological testing should be part of the residency selection process or for career counselling of medical students deciding on their choice of specialty. In fact, in a recent review of the literature on personal- ity and specialty choice, the authors concluded that there is more variation in personality traits within medical specialties than between them. Personality assessment in career counselling was viewed as a tool for medical students to increase their self-knowledge and narrow the number of specialties to explore, but that more than one medical specialty would likely fit the personality of any particular medical student. ${ }^{7}$ For now at least, most institutions employ a standardized interview as part of candidate selection, which in and of itself is a subjective assessment of personality characteristics.

\section{Conclusions}

We have found a significant difference in the normal personality trait of extraversion between urologists and nonurologist surgeons. Both of these groups scored higher than non-surgeons on measures of extraversion. Further study is required before these findings can be applied to the process of candidate selection, evaluation, mentoring and career development.

Competing interests: None declared.

This paper has been peer-reviewed.

\section{References}

1. Eng MK, MacNeily AE, Alden L. The urological personality: Is it unique? Can J Urol 2004;11:2322-7.

2. Costa PT, McCrae RR. Professional Manual: Revised NEO Personality Inventory (NEO PI-R) and NEO Five Factor Inventory (FFI). Odessa, Fl, Psychological Assessment Resources, 1992.

3. King RE. Assessing aviators for personality pathology with the millon clinical multiaxial inventory (MCMI). Aviat Space Environ Med 1995;66:951-6.

4. Callister ID, King RE, Retzlaff PD, et al. Revised NEO personality inventory profiles of male and female US air pilots. Milit Med 1999;164:885-9.

5. Anwar RA, Bosk C, Greenburg AG. Resident Evaluation: Is it, can it, should it be objective? I Surg Res 1981;30:27-41.

6. Markert RJ, Rodenhauser P, El-Baghdadi MM, et al. Personality as a prognostic factor for specially choice: a prospective study of 4 medical school classes. Medscape J Med 2008;10:49.

7. Borges NJ, Savickas ML. Personality and medical specialty choice: a literature review and integration. J Career Assess 2002;10:362-80.

8. Costa PT, McCrae RR. Personality in adulthood: A six-year longitudinal study of self-reports and spouse ratings on the NEO Personality Inventory. J Pers Soc Psych 1988;54:853-63.

9. Magee M, Hojat M. Personality profiles of male and female positive role models in medicine. Psychol Rep 1998;82:547-59.

10. Hojat $M, G$ Glaser $K, X \cup G$, et al. Gender comparisons of medical students' psychosocial profiles. Med Educ 1999:33:442-9.

Correspondence: Dr Andrew E MacNeily, KO-134 BC Children's Hospital, 4480 Oak St., Vancouver, BC V6H 3V4; amacneily@cw.bc.ca 


\title{
The urologist: the life of the party
}

\author{
Edward D. Matsumoto MD, MEd, FRCSC \\ Associate Professor, Division of Urology McMaster University, St. Joseph's Hospital, Hamilton, ON
}

See related article on page 182

Cite as: Can Urol Assoc J 2011;5(3):186-7; D01:10.5489/cuaj.11084

$\mathrm{T}$ his article made me reflect upon what piqued my interest in urology when I began researching medical career options. What was it that initially attracted me to urology? Was it the fact I was able to "combine surgery and medicine in a single specialty" or was it "the variety of surgeries one could do in urology from endourology to the big open cases"? These were definite factors that swayed my decision to enter urology, but I still recall the impact of the urologists I met during my pre-clerkship rotation. Until this point, I was not even aware what urology was or what a urologist did. Early in medical school, our pre-clerkship group was having a session on digital rectal examination and prostate disease. I encountered a very spirited, gregarious and enthusiastic urologist. I could not get over his excitement over teaching a group of medical student how to perform a digital rectal examination. I knew after this experience, this specialty warranted further exploring.

In this issue of the CUAJ, Dr. MacNeily and colleagues compared differences in personality traits between urologists and non-urologist surgeons, as well as between surgeons and non-surgeons. ${ }^{1}$ Overall, the study found urologists to be more extroverted compared to non-urological surgeons and non-surgeons. This study appears to validate my own personal thoughts of the typical urologist's personality. Dealing with "unmentionables" day in and day out does require a certain personality to thrive. But does it really matter what kind of personality you have? Must you have an "extroverted personality" with tendencies for "excitement seeking, gregariousness and positive emotions" to become a successful urologist? Of course not, but it can certainly influence the persona and the dynamics of a residency program. Anecdotally, I have seen how personalities influence resident selection. The candidate's personality is at the forefront of many committee group discussions at the annual Urology Fair. In addition to technical skills and intelligence, how well the candidate worked with the residents, nurses and other staff during an elective rotation is a critical aspect of selection. During the resident selection process, we frequently hear of a candidate's "positive attitude," "upbeat personality" and "outgoing nature." For residents and staff on a residency selection committee, the candidate's personality is an important factor and helps determine the group dynamics of a urology residency program.

Obviously, not all urologists have "extroverted" personality types; there are many "introverted" urologists who are successful and admired by learners, coworkers and patients. A recent study by a group from the University of Minnesota found that the new cohort of residents, the "Generation X," has personality attributes that differ considerably from previous group of surgical residents. ${ }^{2}$ The new generation of surgical residents had more "introverted" personalities, influenced by a more individualistic upbringing partially explained by the loss of traditional family dynamics. Whether the influences of the "Generation X" have an impact on the fabric of urology persona will be an interesting study in the future.

There is something to be said about the personalities of urologists and some truth to the saying "birds of a feather, flock together." And if this is true, it bodes well for our specialty in the future because who wouldn't want to go into a specialty associated with a bunch of outgoing, excitementseeking, gregarious and positive individuals. I'm sure glad I did!

Competing interests: None declared.

This paper has been peer-reviewed. 


\section{References}

1. MacNeily AE, Alden L, Webber E, et al. The surgical personality: comparisons between urologists, nonurologists and non-surgeons.Can Urol Assoc 」 2011;5:182-5; D01:10.5489/cuaj.10142

2. Swanson JA, Antonoff MB, D'Cunha J, et al. Personality profiling of the modern surgical trainee: insights into generation X. J Surg Educ 2010;67:417-20. Epub 2010 Nov 5.
Correspondence: Dr. Edward D. Matsumoto, Division of Urology McMaster University, St. Joseph's Hospital, 50 Charlton Ave. E. G343, Hamilton, ON L8N 4A6; fax: 905-308-7205; matsumo@ memaster.ca 